\title{
Intraoperative Imaging
}

National Cancer Institute

\section{Source}

National Cancer Institute. Intraoperative Imaging. NCI Thesaurus. Code C116490.

Any images taken during an operation; this may be done for a variety of reasons,

including providing the surgeon with immediate feedback to improve operative outcome or to documentation of the procedure. 